\title{
Exaggerated effects of particulate matter air pollution in genetic type II diabetes mellitus
}

\author{
Cuiqing Liu ${ }^{1,2}$, Yuntao Bai ${ }^{2}$, Xiaohua X $u^{2}$, Lixian Sun ${ }^{3}$, Aixia Wang ${ }^{2}$, Tse-Yao Wang ${ }^{2}$, Santosh K Maurya ${ }^{2}$, \\ Muthu Periasamy ${ }^{2}$, Masako Morishita ${ }^{4}$, Jack Harkema ${ }^{5}$, Zhekang Ying ${ }^{6}$, Qinghua Sun ${ }^{2}$ and Sanjay Rajagopalan ${ }^{6 *}$
}

\begin{abstract}
Background: Prior experimental and epidemiologic data support a link between exposure to fine ambient particulate matter $\left(<2.5 \mu \mathrm{m}\right.$ in aerodynamic diameter, $\mathrm{PM}_{2.5}$ ) and development of insulin resistance/Type II diabetes mellitus. This study was designed to investigate whether inhalational exposure of concentrated $\mathrm{PM}_{2.5}$ in a genetically susceptible animal model would result in abnormalities in energy metabolism and exacerbation of peripheral glycemic control.

Methods: KKay mice, which are susceptible to Type II DM, were assigned to either concentrated ambient PM 2.5 or filtered air (FA) for 5-8 weeks via a whole body exposure system. Glucose tolerance, insulin sensitivity, oxygen consumption and heat production were evaluated. At euthanasia, blood, spleen and visceral adipose tissue were collected to measure inflammatory cells using flow cytometry. Standard immnunohistochemical methods, western blotting and quantitative PCR were used to assess targets of interest.

Results: $\mathrm{PM}_{2.5}$ exposure influenced energy metabolism including $\mathrm{O}_{2}$ consumption, $\mathrm{CO}_{2}$ production, respiratory exchange ratio and thermogenesis. These changes were accompanied by worsened insulin resistance, visceral adiposity and inflammation in spleen and visceral adipose depots. Plasma adiponectin were decreased in response to $\mathrm{PM}_{2.5}$ exposure while leptin levels increased. $\mathrm{PM}_{2.5}$ exposure resulted in a significant increase in expression of inflammatory genes and decreased UCP1 expression in brown adipose tissue and activated p38 and ERK pathways in the liver of the KKay mice.
\end{abstract}

Conclusions: Concentrated ambient $\mathrm{PM}_{2.5}$ exposure impairs energy metabolism, concomitant with abnormalities in glucose homeostasis, increased inflammation in insulin responsive organs, brown adipose inflammation and results in imbalance in circulating leptin/adiponectin levels in a genetically susceptible diabetic model. These results provide additional insights into the mechanisms surrounding air pollution mediated susceptibility to Type II DM.

Keywords: Diabetes, Particulate matter, Thermogenesis, Inflammation

\section{Background}

Chronic cardiometabolic disorders such as type 2 diabetes mellitus (Type II DM) have become an uncontrolled epidemic and a burgeoning cause of morbidity and mortality worldwide [1]. As a consequence of rapid increase in combustion of fossil fuels for power generation and transportation, air pollution (indoor and outdoor) has been deemed a major risk factor for death and disability particularly in rapidly developing countries of the world. The cardiovascular and likely metabolic risks posed by inhaled pollutants are

\footnotetext{
* Correspondence: srajagopalan@medicine.umaryland.edu

${ }^{6}$ Division of Cardiovascular Medicine, University of Maryland, Baltimore, MD, USA Full list of author information is available at the end of the article
}

primarily mediated by particulate matter content. Both epidemiologic studies and experimental evidence have provided compelling associations between particulate matter, especially particles $<2.5 \mu \mathrm{m}$ in aerodynamic diameter $\left(\mathrm{PM}_{2.5}\right)$, and cardiometabolic disease [2].

Type II DM and its complications are widely believed to result from unbridled inflammatory pathways in insulin-responsive tissues such as the liver, adipose tissue, skeletal muscle and vasculature [3-5]. Adipose tissue functions as an important endocrine and metabolic organ and controls energy balance and lipid homeostasis. White adipose tissues, including visceral adipose tissue (predominantly epididymal and mesenteric in rodents) 
and subcutaneous adipose tissue (inguinal), serve as the principal energy reservoirs, while brown adipose tissue (BAT) is specialized for energy expenditure and thermogenesis by metabolizing fatty acids and generating heat. $\mathrm{PM}_{2.5}$ exposure has been previously demonstrated to result in an increase in macrophages in visceral fat depots with a shift to a pro-inflammatory phenotype characterized by an increase in F4/80 macrophages and a pro-inflammatory "M1 phenotype" typified by an increase in TNF $\alpha$, IL-6 and a decrease in IL-10, MgI1 gene expression in a dietinduced obesity model [6]. We have also noted multiple abnormalities in mitochondrial rich BAT with $\mathrm{PM}_{2.5}$ exposure over long durations in C57BL/6 mice, accompanied by increase in excess oxidative and nitrosative stress [7]. However, it still remains unknown if $\mathrm{PM}_{2.5}$ accelerates diabetes development in a genetically susceptible model and if $\mathrm{PM}_{2.5}$ influences parameters of energy metabolism. In this study, we examined the hypothesis that inhalation of concentrated $\mathrm{PM}_{2.5}$ would result in abnormalities in energy metabolism and exacerbate peripheral glycemic control through inflammatory mechanisms in a genetically susceptible mouse model of Type II DM.

\section{Methods}

\section{Animals and animal care}

KKay mice (5-week-old) were purchased from Jackson Laboratories (Bar Harbor, ME). All mice were maintained at $21^{\circ} \mathrm{C}$ on a 12 -h light/12-h dark cycle with free access to water and food. The protocols and the use of animals were approved by and in accordance with the Ohio State University Animal Care and Use Committee.

\section{Ambient whole-body inhalational protocol and groups}

KKay mice were exposed by inhalation to either filtered air (FA) or concentrated ambient $\mathrm{PM}_{2.5}$ for $6 \mathrm{~h} / \mathrm{d}$, 5 d/wk from December 282011 to February 28, 2012, for a total of 5 weeks or 8 weeks, in an exposure system ("Ohio Air Pollution Exposure System for Interrogation of Systemic Effects" located at the Ohio State University Animal Facility in Columbus). This exposure system is a mobile trailer versatile aerosol concentration enrichment system which allows concentration of ambient particles $10 \sim 12$ folds. Animal exposure and monitoring of the exposure environment and ambient aerosol were performed as previously described $[6,8]$. For ease of identification, the animal groups were named 5WK-FA, 5WK-PM, 8WK-FA and 8WK-PM ( $\mathrm{n}=7$-8/group). Unless otherwise indicated, $\mathrm{PM}_{2.5}$ refers to concentrated ambient particles in this study.

\section{$\mathrm{PM}_{2.5}$ concentration and composition in the exposure chamber}

To calculate exposure mass concentrations of $\mathrm{PM}_{2.5}$ in the exposure chambers, samples were collected on Teflon filters (PTFE, $37 \mathrm{~mm}, 2 \mu \mathrm{m}$ pore; PALL Life Sciences, Ann Arbor, MI) and weighed before and after sampling in a temperature- and humidity-controlled weighing room using a Mettler Toledo Excellence Plus XP microbalance. Weight gains were used to calculate exposure concentrations. Elemental composition was determined by high-resolution inductively coupled plasma-mass spectrometry (ICSP-MS) (ELEMENT2, Thermo Finnigan, San Jose, CA).

\section{Measurements of blood glucose homeostasis and insulin sensitivity}

Before and subsequent to the exposure to FA or $\mathrm{PM}_{2.5}$, mice were fasted for intra-peritoneal glucose tolerance testing (IPGTT) or insulin tolerance test (ITT) as previously described. Briefly, mice were fasted overnight and dextrose ( $2 \mathrm{mg} / \mathrm{g}$ body weight) was injected intraperitoneally for IPGTT. Blood sample was collected from the vena caudalis and blood glucose measurement was conducted with an Contour Blood Glucose Meter (Bayer, Mishawaka, IN) at baseline, and 30, 60, 90, and 120minutes after the dextrose injection. When ITT was performed, insulin $(0.5 \mathrm{U} / \mathrm{kg})$ was administered by intraperitoneal injection after 4.5hours fasting. Blood glucose measurement was conducted in the same way as IPGTT with the same Contour Blood Glucose Meter at baseline, and 30,60, 90, and 120minutes after insulin injection.

Adiponectin and leptin levels were determined by the mouse adiponectin kit (PerkinElmer, Boston, MA) or leptin quantification kit (Abcam, Cambridge, MA) following the manufacturer's instructions.

\section{Oxygen consumption and heat production measurement}

The mice were isolated in a semi-sealed cage, and the inner air was aspirated at a constant volume/min. Oxygen consumption, $\mathrm{CO}_{2}$ production, respiratory exchange ratio and heat production were measured simultaneously using a computer-controlled, open-circuit Oxymax/ CLAMS System (Columbus Instruments, Columbus, $\mathrm{OH})$. Each mouse was measured individually in a resting state at $22^{\circ} \mathrm{C}$ in the presence of food and water. Measurements were taken for a 24-h period, including a 12-h light cycle and a 12-h dark cycle. Data were normalized to body weight.

\section{Immunoblotting}

Protein levels were determined by western blot. Tissues of brown adipose and liver were homogenized with M-PER Mammalian protein extraction reagent (Thermo Scientific, Rockford, IL) on ice. Equal quantities of proteins from these tissues were loaded and separated by 10\% SDS-PAGE. Following transfer to immobilon-P polyvinylidene difluoride (PVDF) membrane and blocking with 5\% nonfat milk, the blots were incubated with different primary antibodies: 
UCP1 (Abcam, Cambridge, MA), P-AKT (phosphorylation at Ser473)/AKT, PI3K, P-AMPK (phosphorylation at Thr172)/AMPK, MAPK pathway proteins (Cell Signaling Technology, Danvers, MA). The immunoblots were then incubated with a secondary antibody conjugated with horseradish peroxidase and visualized with enhanced chemiluminescence, and the autoradiograph was quantitied by densitometric analysis with ImageJ software. $\beta$-actin was used as control reference.

\section{Flow cytometric evaluation of inflammation in blood/tissues} Epididymal white adipose tissue (epiWAT) was excised, minced, and digested with collagenase type II, and the stromal vascular fraction isolated as described previously. Spleens were isolated, homogenized and suspended in PBS. Bone marrow derived cells were collected by flushing the femur and tibia with PBS. These cells were centrifuged at $500 \times \mathrm{g}$ for $5 \mathrm{~min}$. Whole blood was centrifuged at $500 \times \mathrm{g}$, $4^{\circ} \mathrm{C}$ for $5 \mathrm{~min}$ and plasma was collected. The remaining blood cells and the resulting pellets were re-suspended in $1 \mathrm{X}$ red blood cell lysis buffer (Biolegend, San Diego, CA), at room temperature for 3 minutes followed by addition of $1 \mathrm{X}$ PBS and centrifugation. Then, blood cells, spleen cells and bone marrow derived cells were stained with anti-CD11b, anti-7/4 and anti-Gr-1, stromal vascular fraction was stained with anti-CD11c and F4/80, both followed by incubation at room temperature for 45 minutes. Cells were subsequently washed with $1 \mathrm{X}$ PBS and resuspended in $1 \%$ neutral buffered formalin and run by flow cytometry (BD FACS LSR II ${ }^{\mathrm{Tm}}$ flow cytometer, Becton Dickinson, San Jose, CA). Data was analyzed using BD FACS Diva software (Becton Dickinson, San Jose, CA). All antibodies were purchased from Biolegend, Miltenyi Biotec, or BD Bioscience.

\section{Quantitative RT-PCR}

RT-PCR was performed using RNA extracted from different tissues of the experimental mice. Splenic cells from 8-week exposed KKay mice were seeded in one 24-well plate with $1.0 \times 10^{6} /$ well and treated with antiCD3 (BD Biosciences, San Jose, CA) at a concentration of $1 \mu \mathrm{g} / \mathrm{ml}$ for different period. Cells were collected at the end of incubation. Total RNA from brown adipose tissue or splenic cells was isolated with Trizol (Invitrogen, Carlsbad, CA, USA) according to the manufacturer's protocol. cDNA was reversely transcribed using High Capacity cDNA Transcription kit (Applied Biosystems, Carlsbad, California, USA). Quantitative polymerase chain reaction (qPCR) was performed in duplicate using the lightcycler 480. "No template", cDNA negative controls were included for each gene set in all PCR reactions to detect contamination. The expression level for each gene was calculated using the $\Delta \mathrm{Ct}$ method relative to $\beta$-actin. The sequences of all primers are listed in Table 1.

\section{Wire myograph and pressurized myograph studies}

After the mice were sacrificed by isoflurane inhalation, vascular function of thoracic aorta was evaluated as previously [9]. Briefly, aorta with adhesive tissue were dissected out and placed in a dissecting dish filled with icecold oxygenated Krebs solution of the following composition (in mM): $\mathrm{NaCl} 119, \mathrm{KCl} 4.7, \mathrm{NaHCO}_{3} 25$, $\mathrm{CaCl}_{2}$ 2.5, $\mathrm{MgCl}_{2} 1, \mathrm{KH}_{2} \mathrm{PO}_{4} 1.2$, and D-glucose 11. After careful removal of adherent connective tissue, the artery was cut into $2 \mathrm{~mm}$-length ring segments. The ring was suspended between two stainless bins in a 5-ml chamber on a Multi Myograph (Danish, Myo Technology A/S, Denmark) as previously described. Krebs solution in the bathing chamber was constantly bubbled with $95 \%$ $\mathrm{O}_{2}-5 \% \mathrm{CO}_{2}$ and maintained at $37^{\circ} \mathrm{C}$ ( $\mathrm{pH}$ 7.4). Following 60 mins equilibration, each ring was stretched to $5 \mathrm{mN}$, a determined optimal resting tone for the development of isometric contraction. After artery contractility was tested, phenylephrine (1 $\mu \mathrm{M}$, submaximal concentration) was used to contract the rings, followed by dose response of acetylcholine $(30 \mathrm{nM}-10 \mu \mathrm{M})$ in aorta. The rings were then rinsed in pre-warmed, oxygenated Krebs solution several times until a stable resting tone returned and finally equilibrated for 60 mins. The resting tone was readjusted to $5 \mathrm{mN}$ if necessary. And then, insulin $(0.1 \mathrm{U} / \mathrm{ml}-10 \mathrm{U} / \mathrm{ml})$-induced relaxation was tested.

For pressure myograph studies, function of segments of resistance mesenteric arteries (2nd order) was evaluated as described [10]. Briefly, artery rings were dissected in Krebs solution, and cannulated between two glass cannulas with tip diameter $<100 \mu \mathrm{m}$ in a chamber filled with Krebs solution bubbled by $95 \% \mathrm{O}_{2} / 5 \% \mathrm{CO}_{2}$ and maintained at $37^{\circ} \mathrm{C}(\mathrm{pH} \mathrm{7.4)}$. The intraluminal pressure was monitored, and vessel diameter was recorded by a light-inverted microscope with video camera monitored with the automated software Myo-View software (Danish Myo, Denmark). For testing endothelial responsiveness, phenylephrine $(5 \mu \mathrm{M})$ was added to induce stable contraction at $100 \mathrm{mmHg}$ intraluminal pressure and various doses of acetylcholine was used to test endothelial response at constant shear. The same setting was used for all the groups. After washing the vessel at the end of this intervention, graded doses of phenylephrine was tested to assess response. At the end of experiment, passive dilation was achieved by changing the bathing solution to $\mathrm{Ca}^{2+}$ free Krebs solution. Data was expressed as \% of maximal $\mathrm{KCl}$ tone for phenylephrine and as \% of phenylephrine tone $(5 \mu \mathrm{M})$ for acetylcholine.

\section{Data analysis}

Data are expressed as means \pm standard error of the mean unless otherwise indicated. Graphpad Prism software (Version 5) was used for Student's $t$ test when 2 groups (PM and FA group) were compared. 
Table 1 Primers used for real-time PCR

\begin{tabular}{|c|c|c|}
\hline Primer & Forward oligonucleotides & Reverse oligonucleotides \\
\hline$\overline{U C P 1}$ & ACTGCCACACCTCCAGTCATT & CTITGCCTCACTCAGGATTGG \\
\hline PGCla & GAGAATGAGGCAAACTTGCTAGCG & TGCATGGTTCTGAGTGCTAAGACC \\
\hline PRDM16 & CAGCACGGTGAAGCCATTC & GCGTGCATCCGCTTGTG \\
\hline Cidea & ATCACAACTGGCCTGGTTACG & TACTACCCGGTGTCCATTTCT \\
\hline Elovi3 & GATGGTTCTGGGCACCATCTT & CGTTGTTGTGTGGCATCCTT \\
\hline CPT1M & TGCCTITACATCGTCTCCAA & GGCTCCAGGGTTCAGAAAGT \\
\hline$F 4 / 80$ & TGTCTGACAATTGGGATCTGCCCT & TTGCATGTTCAGGGCAAACGTCTC \\
\hline INFY & GCTCTGAGACAATGAACGCT & AAAGAGATAATCTGGCTCTGC \\
\hline$I L-4$ & TCGGCATTITGAACGAGGTC & GAAAAGCCCGAAAGAGTCTC \\
\hline TNFa & TTCCGAATTCACTGGAGCCTCGAA & TGCACCTCAGGGAAGAATCTGGAA \\
\hline IL-6 & ATCCAGTTGCCTTCTTGGGACTGA & TAAGCCTCCGACTTGTGAAGTGGT \\
\hline$\beta$-actin & TGTGATGGTGGGAATGGGTCAGAA & TGTGGTGCCAGATCTTCTCCATGT \\
\hline
\end{tabular}

Concentration-relaxation curves were analyzed by twoway ANOVA followed by Bonferroni's post-tests. $P$ value of $<0.05$ was considered statistically significant.

\section{Results}

\section{Exposure characteristics}

The mean daily ambient $\mathrm{PM}_{2.5}$ concentration at the study site in Columbus, $\mathrm{OH}$, was $8.28 \pm 0.65 \mu \mathrm{g} / \mathrm{m}^{3}$. The mean concentration of $\mathrm{PM}_{2.5}$ was $1.51 \pm 0.38 \mu \mathrm{g} / \mathrm{m}^{3}$ in the filtered air chamber, and $102.9 \pm 19.16 \mu \mathrm{g} / \mathrm{m}^{3}$ in the exposure chamber respectively. This represented 12.4fold concentration over ambient levels (Additional file 1: Figure S1). For the purposes of convenience concentrated ambient $\mathrm{PM}_{2.5}$ exposure is referred to $\mathrm{PM} / \mathrm{PM}_{2.5}$ in this manuscript unless specified otherwise. Detailed elemental characterization of the exposure environment is provided in Table 2. Many trace elements including S, Ba, $\mathrm{Zn}, \mathrm{Ca}$, $\mathrm{Mn}$ and $\mathrm{Mg}$, were elevated.

\section{Effect of $\mathrm{PM}_{2.5}$ on energy homeostasis in KKay mice}

Since KKay mice are well known to develop severe abnormalities in peripheral glycemic control and insulin over 10 weeks [11], we exposed 5-week old KKay mice to $\mathrm{PM}_{2.5}$ for 5- or 8-week periods and evaluated the whole body energy homeostasis. As shown in Figure 1, $\mathrm{PM}_{2.5}$ inhalation for 5 weeks significantly altered energy metabolism evidenced by decreased $\mathrm{O}_{2}$ consumption, $\mathrm{CO}_{2}$ production and heat production, $P<0.001$ compared to respective FA group (Figure 1, A, B, D). Prolonged exposure (8 weeks) showed no further effect on these parameters (Figure 1, A-D). After 5 weeks exposure to $\mathrm{PM}_{2.5}$, we found significant decrease in respiratory exchange ratio, $\mathrm{P}<0.05$ compared to FA (Figure 1C). Although there was no difference between FA and PM groups in respiratory exchange ratio after 8 weeks $\mathrm{PM}_{2.5}$ exposure when the data from entire duration of 24 hrs (Light + Dark Phase) were analyzed, analysis data from the Dark phase showed significant decrement in respiratory exchange ratio (Figure $1 \mathrm{C}-\mathrm{c} 2$ ).

Effect of $\mathrm{PM}_{2.5}$ on glucose homeostasis in KKay mice To test whether $\mathrm{PM}_{2.5}$ exposure detrimentally affects glucose control, we performed intra-peritoneal glucose tolerance test and insulin tolerance test in exposed mice. As shown in Figure 2A and 2D, there was no difference at baseline in glucose tolerance or insulin sensitivity prior to assignment to exposure. Mice showed significant elevations in glucose levels in response to intraperitoneal glucose challenge, after 5-weeks of $\mathrm{PM}_{2.5}$ exposure but no significant difference after 8-weeks of exposure (Figure 2, B-C). Blood glucose was attenuated in response to insulin in $\mathrm{PM}_{2.5}$ exposed mice when compared to FA group after 5-weeks of exposure (Figure 2E). However, after 8-week exposure, standardized intraperitoneal injection of insulin did not decrease blood glucose in either the FA or PM groups, with the blood glucose maintained at their initial levels during the 120-minute post-administration period (Figure 2F).

\section{Body and organ weight measurements}

Figure 3 illustrates the body and organ weights after 5-week or 8-week exposure to $\mathrm{PM}_{2.5}$ or FA. There were no significant differences in the body weight (Figure 3A) after the exposure. Interestingly, although the liver weight in $\mathrm{PM}_{2.5}$-exposed group was comparable to that in FA group after the 5-week exposure, mice in the 8-week $\mathrm{PM}_{2.5}$ exposure showed a clear trend to decrease when compared with the 5-week FA-exposed group (Figure $3 \mathrm{~B}$ ). The spleen weight was significantly lower in mice exposed to $\mathrm{PM}_{2.5}$ than that in FA-exposed mice at both 5 -week and 8-week time points (Figure $3 \mathrm{C}$ ). Although there was no difference in the weight of eWAT between $8 \mathrm{WK}-\mathrm{FA}$ and $8 \mathrm{WK}-\mathrm{PM}$ groups, a substantial trend $(P=0.0578)$ towards an increase in the adipose 
Table 2 Elemental constituents from OASIS in Columbus December 2011 to February 2012 by ICP-MS

\begin{tabular}{|c|c|c|c|c|c|c|}
\hline \multirow[t]{2}{*}{ Elements } & \multicolumn{2}{|c|}{ Ambient $\mathrm{PM}_{2.5}$} & \multicolumn{2}{|c|}{ Filtered Air } & \multicolumn{2}{|c|}{ Concentrated $\mathrm{PM}_{2.5}$} \\
\hline & Mean & SD & Mean & SD & Mean & SD \\
\hline S & 700.1 & 169.1 & BID & 50.3 & 6124.7 & 3789.4 \\
\hline $\mathrm{Ca}$ & 69.8 & 24.5 & 66.6 & 46.7 & 504.1 & 335.5 \\
\hline $\mathrm{Na}$ & 60.4 & 16.2 & 41.1 & 28.5 & 353.2 & 218.1 \\
\hline $\mathrm{Fe}$ & 42.8 & 25.0 & 24.3 & 27.0 & 341.9 & 246.2 \\
\hline K & 38.7 & 18.2 & 24.2 & 20.7 & 255.3 & 182.0 \\
\hline $\mathrm{Zn}$ & 24.3 & 17.8 & 9.4 & 14.6 & 205.5 & 201.8 \\
\hline $\mathrm{Mg}$ & 17.2 & 7.7 & 11.0 & 6.1 & 122.2 & 76.8 \\
\hline $\mathrm{Al}$ & 15.1 & 11.8 & 20.3 & 26.3 & 123.5 & 138.2 \\
\hline P & 14.3 & 10.5 & 14.5 & 6.3 & 96.4 & 105.7 \\
\hline $\mathrm{Pb}$ & 3.5 & 1.6 & BID & 0.5 & 24.9 & 17.7 \\
\hline $\mathrm{Cu}$ & 2.5 & 1.2 & 1.6 & 2.5 & 18.3 & 11.9 \\
\hline $\mathrm{Ba}$ & 2.2 & 0.9 & 0.7 & 0.7 & 17.2 & 10.9 \\
\hline $\mathrm{Mn}$ & 1.6 & 0.7 & 0.5 & 0.4 & 12.9 & 9.4 \\
\hline $\mathrm{Cr}$ & 2.0 & 0.4 & 4.4 & 1.8 & 5.9 & 3.0 \\
\hline Se & 0.6 & 0.2 & 0.0 & 0.0 & 5.6 & 3.6 \\
\hline $\mathrm{Ti}$ & 0.6 & 0.3 & 0.1 & 0.1 & 4.9 & 3.2 \\
\hline $\mathrm{Sb}$ & 0.6 & 0.2 & 0.0 & 0.0 & 4.3 & 2.6 \\
\hline $\mathrm{Sr}$ & 0.3 & 0.2 & 0.2 & 0.1 & 2.9 & 1.8 \\
\hline As & 0.4 & 0.1 & 0.0 & 0.0 & 3.4 & 2.1 \\
\hline Mo & 0.4 & 0.1 & 0.3 & 0.3 & 2.7 & 1.7 \\
\hline $\mathrm{Ni}$ & 0.2 & 0.3 & BID & 0.6 & 1.7 & 1.8 \\
\hline V & 0.2 & 0.1 & 0.0 & 0.0 & 1.4 & 1.0 \\
\hline $\mathrm{Cd}$ & 0.1 & 0.0 & 0.1 & 0.0 & 0.9 & 0.6 \\
\hline $\mathrm{Rb}$ & 0.1 & 0.0 & 0.0 & 0.0 & 0.6 & 0.4 \\
\hline $\mathrm{Ce}$ & 0.0 & 0.0 & 0.0 & 0.0 & 0.4 & 0.4 \\
\hline La & 0.0 & 0.0 & 0.0 & 0.0 & 0.2 & 0.2 \\
\hline Co & 0.0 & 0.0 & 0.0 & 0.0 & 0.2 & 0.2 \\
\hline
\end{tabular}

Concentrations in $\mathrm{ng} / \mathrm{m}^{3}$.

BID: below instrument detection limit.

tissue weight was shown after 5-weeks of $\mathrm{PM}_{2.5}$ inhalation (Figure 3D). We also examined the weight of subcutaneous (inguinal) WAT (Iwat) and (interscapular) BAT and observed no effect of $\mathrm{PM}_{2.5}$ on fat weights in both the 8-week and 5-week exposed animals (Figure 3, E-F).

\section{Effect of $\mathrm{PM}_{2.5}$ exposure on circulating cytokines and adipokines}

We measured inflammatory biomarkers in the blood to see if $\mathrm{PM}_{2.5}$ exposure could exaggerate systemic inflammation. As shown in Figure 4A, we did not find any significant differences in plasma IL-12p70, IFN- $\gamma$, IL-6, TNF $\alpha$, or MCP-1 between FA and PM groups at either the 5-week or 8-week periods. The levels of IL-10 were too low to be detectable. As shown in Figure 4B, the levels of plasma adiponectin were decreased by 5 -week $\mathrm{PM}_{2.5}$ exposure accompanied by an increase in leptin levels when compared to FA controls $(P<0.05)$ suggesting alterations in this key adipokine in response to $\mathrm{PM}_{2.5}$ exposure [12]. There were no additional changes in adiponectin or leptin levels at the 8-week exposure (Figure 4B).

\section{Peripheral inflammation by $\mathrm{PM}_{2.5}$ in KKay mice}

Because prior studies have demonstrated an increase in circulating inflammatory monocytes in response to air pollution exposure [13], we investigated this population of cells in $\mathrm{PM}_{2.5}$-exposed KKay mice. As shown in Figure 5, $\mathrm{PM}_{2.5}$ exposure increased $\mathrm{CD} 11 \mathrm{~b}^{+} \mathrm{Gr}-1^{\text {low }} 7 / 4^{\mathrm{hi}}$ cells, the inflammatory monocytes, in the peripheral circulation (Figure 5B) with a corresponding trend towards a reduction in this population in the bone marrow (Figure 5C). Although there were no differences in splenic $\mathrm{CD} 11 \mathrm{~b}^{+} \mathrm{Gr}-1^{\text {low }} 7 / 4^{\text {hi }}$ cells (Figure $5 \mathrm{D}$ ), IFN $\gamma$ production from splenocytes of $\mathrm{PM}_{2.5}$-exposed mice was significantly higher compared to that of FA mice with a corresponding decrease in IL-4 release (Figure 5E). These results suggest a redirection of Th1/Th2 balance towards a Th1 polarized state in response to $\mathrm{PM}_{2.5}$ exposure.

We investigated inflammatory cell content in eWAT, which is regarded to play an important role in the development of IR, obesity, and type 2 diabetes mellitus [14-16]. In eWAT, we observed an increase in $\mathrm{F} 4 / 80^{+} / \mathrm{CD} 11 \mathrm{c}^{+}$cells in response to 5-week $\mathrm{PM}_{2.5}$ exposure (Figure 6). Although there was no difference between the two groups after 8 -weeks, this population in both groups surged to as high as $70 \%$ at 8 weeks, while this subset constituted $25-40 \%$ of the $\mathrm{F} 4 / 80^{+} / \mathrm{CD} 11 \mathrm{c}^{+}$cells after 5 -week $\mathrm{PM}$ exposure (Figure 6B).

\section{Brown adipocyte-specific and inflammation gene profiles expression in BAT}

In light of the significant change in thermogenesis (Figure 1), we investigated uncoupling protein 1 (UCP1), a key player in thermogenesis via uncoupling of oxidative phosphorylation [17,18]. UCP1 protein (Figure 7A) but not mRNA level (Figure 7B) was down-regulated in interscapular BAT of $\mathrm{PM}_{2.5}$ exposed mice for both 5-week and 8-week exposure, consistent with decreased thermogenic activity (Figure 1). To determine brown adipocyte-specific gene profiles in diabetic mice in response to $\mathrm{PM}_{2.5}$ exposure, we examined several key genes related to mitochondrial function and regulatory networks that govern expression of genes during BAT differentiation and mitochondrial biogenesis by real-time PCR in the BAT. These genes include the expression of $P g c-1 \alpha$ (PPAR gamma coactivator $1 \alpha$ ), Prdm16 (a master regulator of brown adipocyte specification and differentiation), CPT-1 M (Carnitine palmitoyltransferase 1 muscle isoform), Cidea (a lipid droplet-associated protein with a role in fat storage) and Elovl3 (an elongase enzyme important 


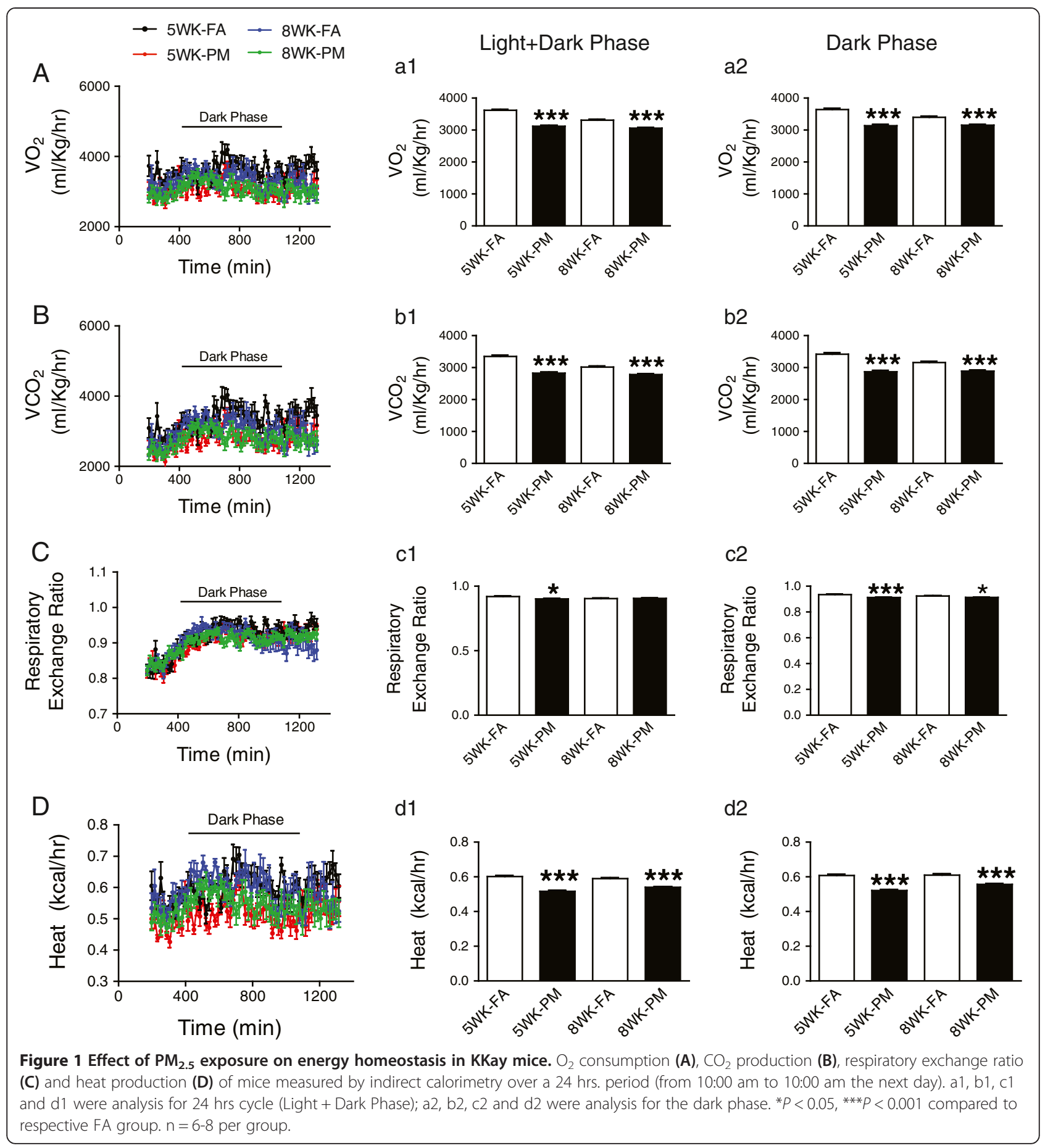

for elongation of monounsaturated or saturated very long chain fatty acids). However, no differences were observed except for the gene expression of Elovl3 was inhibited in response to $\mathrm{PM}_{2.5}$ exposure (Figure $7 \mathrm{~B}$ ). Although no significant upregulation of F4/80, was observed, an increase in IL-6 and TNF $\alpha$ was noted in BAT after 5week or 8-week $\mathrm{PM}_{2.5}$ exposure (Figure $7 \mathrm{C}$ ), indicating $\mathrm{PM}_{2.5}$ induced inflammation in BAT. Thus, alterations of
UCP1 via post-transcriptional mechanisms and inflammation may account for the decreased thermogenesis and oxygen consumption in response to $\mathrm{PM}_{2.5}$ exposure.

Defective insulin signaling in liver in response to $\mathrm{PM}_{2.5}$ As shown in Figure 8A, phosphorylated AKT (Ser473) was reduced in liver from $\mathrm{PM}_{2.5}$ group vs. respective FA group after 5-week exposure, without further alteration 

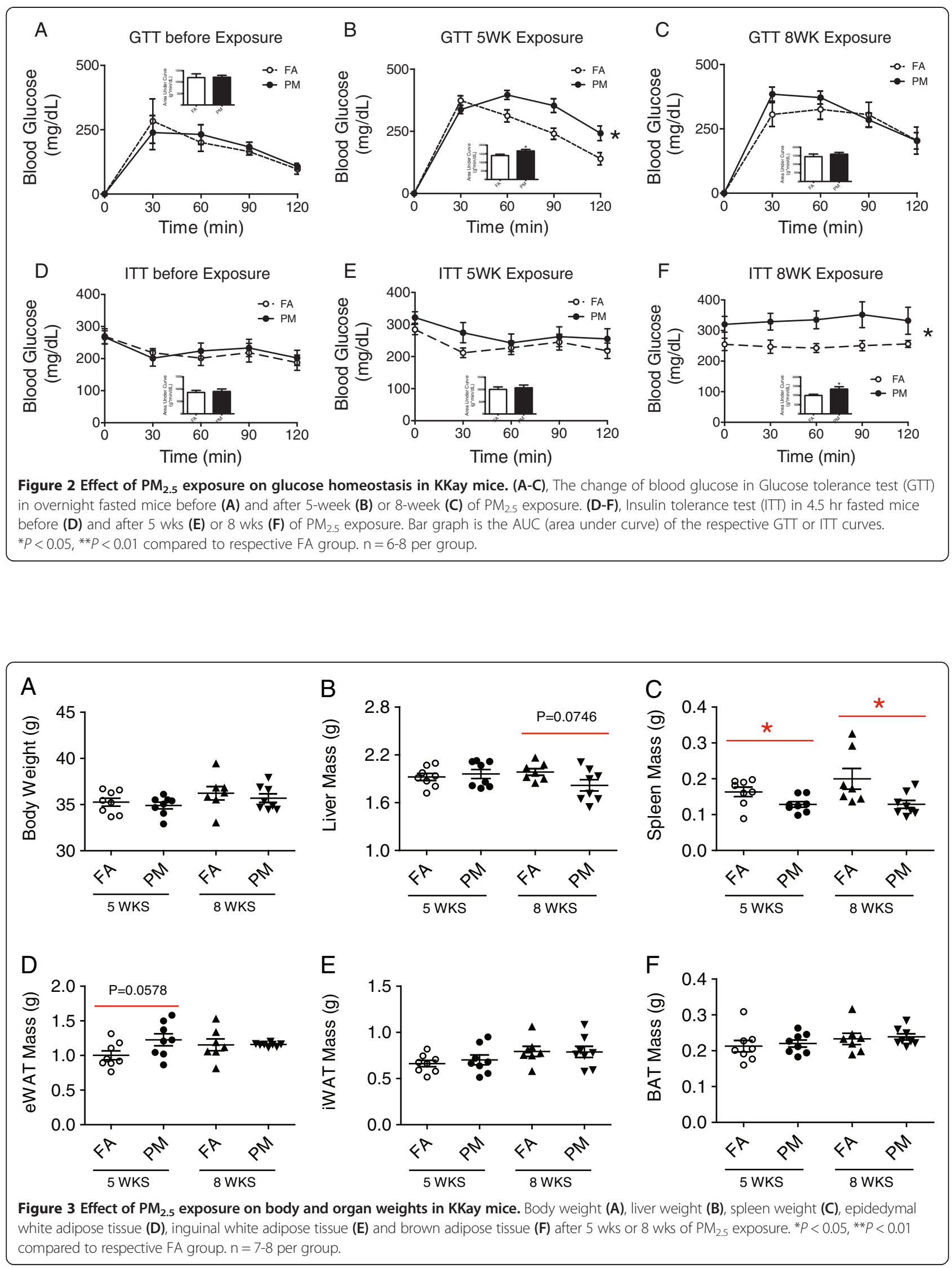


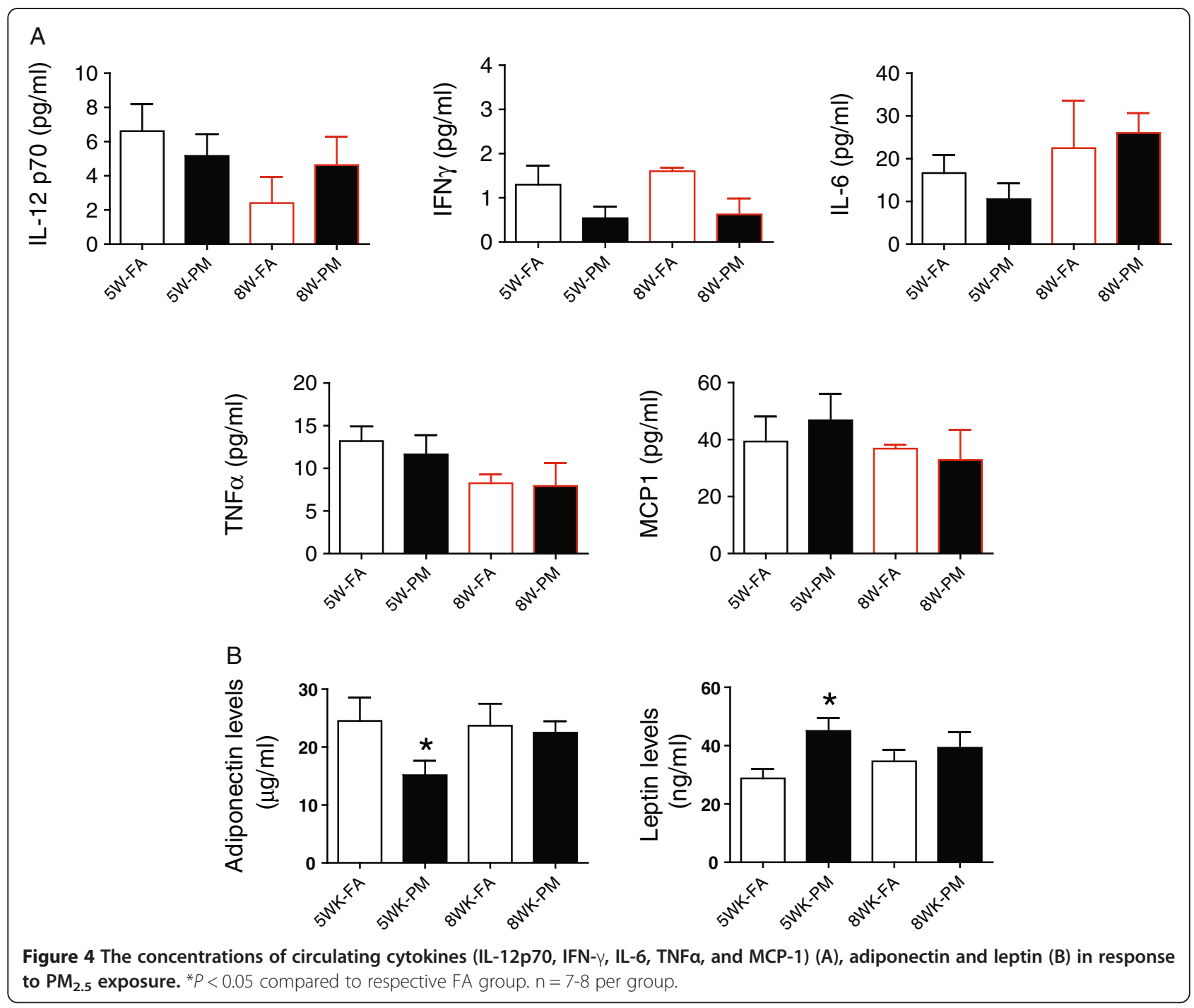

after 8-weeks of exposure. No alteration was seen in PI3K expression between all groups (Figure $8 \mathrm{~B}$ ). There was a slight trend towards decrease in the phosphorylation levels of AMPK (Thr172) in KKay mice with $\mathrm{PM}_{2.5}$ exposure at 5 and 8-weeks compared with FA controls (Figure 8C). Notably, the 8-week FA group showed decreased AMPK phosphorylation compared to the 5-week FA counterparts, indicating progressive worsening of disease in the mice over time. To further explore mechanisms by which $\mathrm{PM}_{2.5}$ impaired glucose homeostasis and hyperlipidemia, we assessed inflammatory signals implicated in hepatic IR. No further increase in F4/80 content in the liver of mice (Figure 8D) were noted with $\mathrm{PM}_{2.5}$ exposure, in excess of that noted in FA at both time points. Immunoblotting analysis demonstrated increased levels of activated p38 and ERK, but not JNK, in the liver of the mice exposed to $\mathrm{PM}_{2.5}$ for 5-weeks, compared to that in the mice exposed to FA (Figure 8, E-G). Compared to 5WK-FA group, there was a trend towards an increase in levels of p38 and ERK in the liver of both FA mice and PM mice exposed for 8 weeks. However, we observed no significant change in the $8 \mathrm{WK}-\mathrm{PM}$ group compared to that in FA group (Figure 8, E-F).

\section{$\mathrm{PM}_{2.5}$ does not exacerbate endothelial dysfunction in KKay mice}

Exaggerated constriction of small mesenteric arterioles in response to phenylephrine with no alteration in response to acetylcholine was noted with $\mathrm{PM}_{2.5}$ exposure (Additional file 1: Figure S2A). Responses to acetylcholine and insulin mediated vasodilation in conduit arterial segments (aorta) were also profoundly diminished, consistent with marked hyperglycemia and hyperinsulinemia in the KKay model with no further alteration after $\mathrm{PM}_{2.5}$ exposure (Additional file 1: Figure S2B).

\section{Discussion}

In this paper we evaluated the role of ambient air pollution on energy metabolism, glucose homeostasis, and 


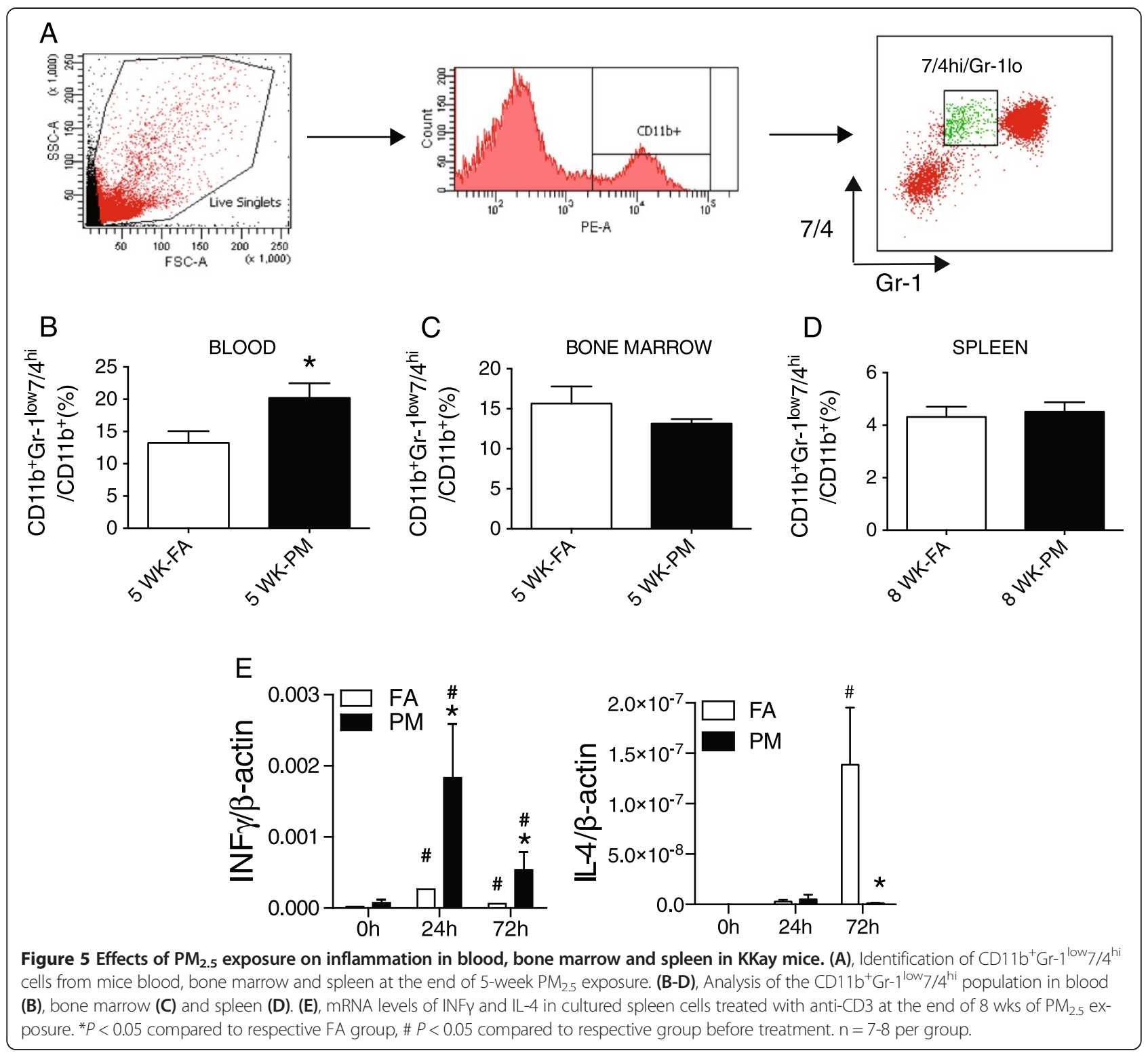

inflammatory signaling pathways in a genetically predisposed model that develops severe Type II DM within 6-10 weeks. There are several important findings in this study that support an adjunctive role of air-pollution exposure in potentiating development of Type II DM. Firstly, $\mathrm{PM}_{2.5}$ exposure had effects on energy metabolism including reduction of $\mathrm{O}_{2}$ consumption, $\mathrm{CO}_{2}$ production, respiratory exchanging ratio and heat generation. Secondly, $\mathrm{PM}_{2.5}$ exposure exaggerated IR, visceral adiposity and peripheral inflammatory response. Thirdly, $\mathrm{PM}_{2.5}$ exposure resulted in lowered UCP1 expression in BAT together with increased expression of inflammatory genes. Finally, $\mathrm{PM}_{2.5}$ exposure resulted in activation of p38 and ERK but not JNK in the liver of KKay mice.

There is increasing evidence suggesting links between exposure to environmental toxins and susceptibility to
Type II DM. Consistent with the study in a diet-induced obesity model $[6,8,19], \mathrm{PM}_{2.5}$ elevated blood glucose levels and impaired insulin signaling evidenced by reduced Akt phosphorylation in the genetic KKay mice. These results indicate the reproducible effect of air pollution in mediating adverse metabolic consequences in a genetically susceptible model of Type II DM. Thus it provides additional experimental evidence to support the association between $\mathrm{PM}_{2.5}$ and cardiometabolic disease.

One of the central findings of this study is the changes in metabolic indices demonstrated in carefully performed metabolic cage studies. Recent studies have suggested a compelling role for BAT in regulating metabolism and insulin resistance [20-22]. Brown adipocytes play an important role in dissipation of energy in the form of heat, a process called non-shivering thermogenesis. 


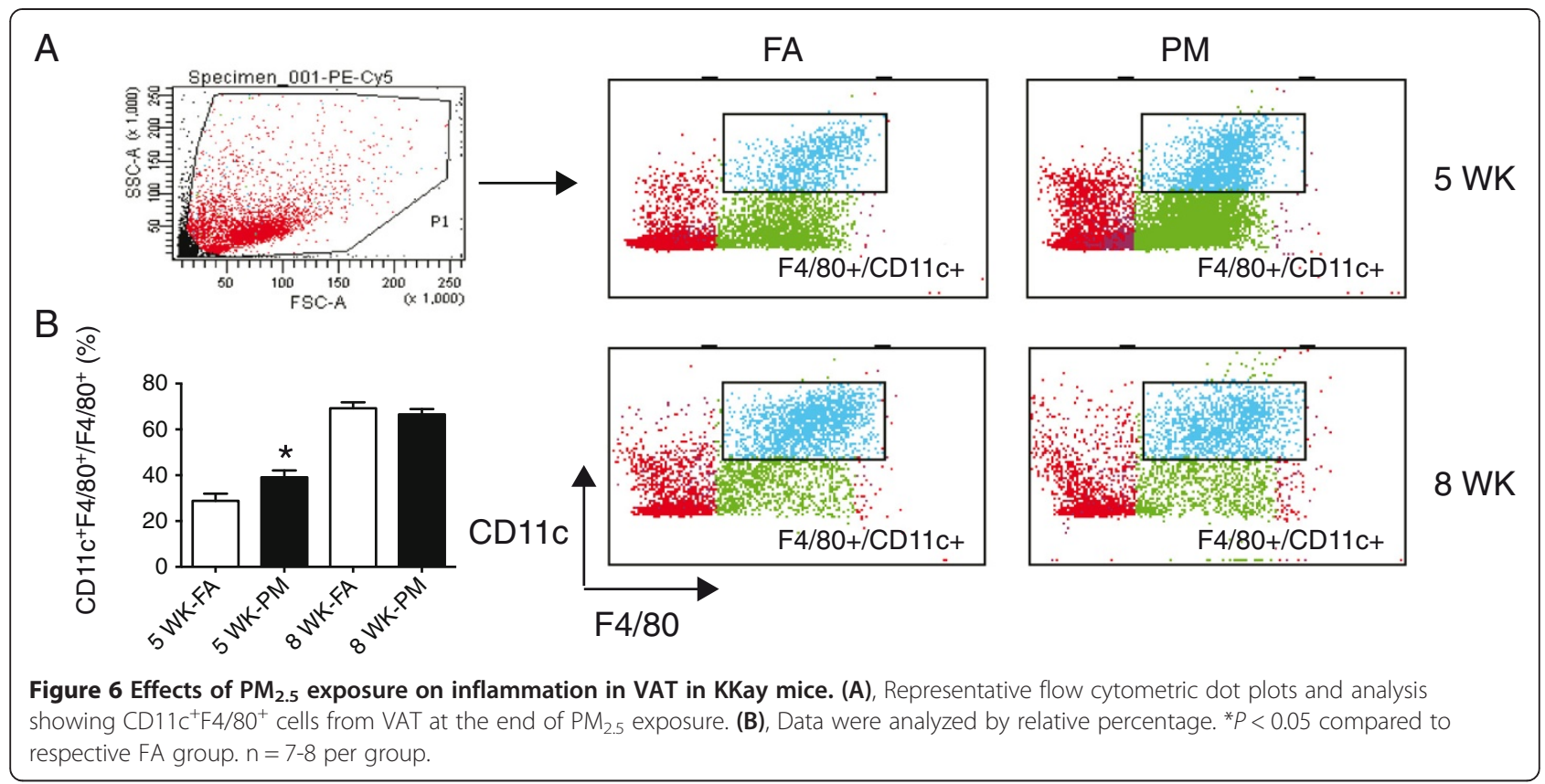

A reduction in thermogenic function of BAT has been linked to the development of IR and obesity [20-22]. UCP1, which is specifically expressed in BAT mitochondria, is largely responsible for the uncoupling of respiration from ATP synthesis resulting in dissipation of energy as heat, playing a pivotal role in thermogenesis [23]. We have previously demonstrated abnormalities in BAT structure and function with chronic exposure to $\mathrm{PM}_{2.5}$ [7]. These changes include electron microscopic changes in BAT mitochondria as well as transcriptional reprogramming of BAT genes which include UCP1 expression.

The substantial down-regulation of UCP1 protein in BAT in the $\mathrm{PM}_{2.5}$ exposed mice may potentially account for decreased heat production and thereby explain reduction in $\mathrm{O}_{2}$ consumption and $\mathrm{CO}_{2}$ production. Interestingly, high fat diet treated mice showed substantial compensatory increase in the expression of UCP1 both at the protein levels and mRNA levels, likely representing an adaptive mechanism to excess caloric intake [24]. Fromme et al. summarized 62 relevant studies of which 42 studies have previously demonstrated that high fat diet itself enhanced UCP1 expression [25]. Thus our findings suggest a unique role of $\mathrm{PM}_{2.5}$ exposure in preventing the adaptive increase of UCP1. These findings are consistent with our previous studies showing that long term $\mathrm{PM}_{2.5}$ exposure reduced UCP1 expression in C57B/L6 mice [7]. An important point in our study that deserves further explanation is the finding that in many end-points we observed a difference at 5 weeks but not at 8 weeks. It is possible that the severity of phenotype at 8 weeks in the KKay makes it very difficult to distinguish end-points at 8 weeks between groups.
White adipose tissue is a major source of energy for the human body. The increased epididymal (visceral) fat mass in mice exposed to concentrated $\mathrm{PM}_{2.5}$ demonstrated that $\mathrm{PM}_{2.5}$ inhalation induced visceral adiposity likely through adipocyte hypertrophy (indicating excess energy storage which was supported by decreased energy expenditure in $\mathrm{PM}_{2.5}$-exposed KKay mice) and enhanced inflammatory cell infiltration. Macrophages in the adipose tissue have been shown to increase from $10-15 \%$ to $45-60 \%$ of total cellular content during obesity and may independently have contributed to expansion of VAT mass [26]. In addition, the adipose tissue is also a source of major adipocytokines such as adiponectin and leptin. The expression of adiponectin decreased with increase in the adiposity and reduction of adiponectin has been associated with insulin resistance, dyslipidemia, and atherosclerosis in humans [27]. In line with this, circulating adiponectin levels were significantly reduced by $\mathrm{PM}_{2.5}$ inhalation as has been shown by us previously [6]. Adiponectin plays an important role in mediating insulin-sensitization through binding to its receptors AdipoR1 and AdipoR2, leading to activation of adenosine monophosphate dependent kinas (AMPK) and presumably other yet-unknown signaling pathways. A trend towards a decrease in AMPK phosphorylation in liver of the KKay mice exposed to $\mathrm{PM}_{2.5}$ could potentially be attributable to reduced adiponectin release. Leptin is another major adipokine from adipose tissue. Contrary to the remarkably decreased circulating leptin levels in response to $\mathrm{PM}_{2.5}$ exposure in C57BL/6 mice fed on regular chow [7], we observed an increase in leptin levels in the $\mathrm{PM}_{2.5}$ inhaled KKay mice. The 
A
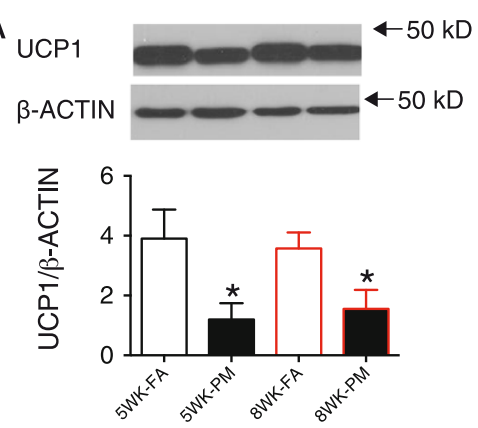

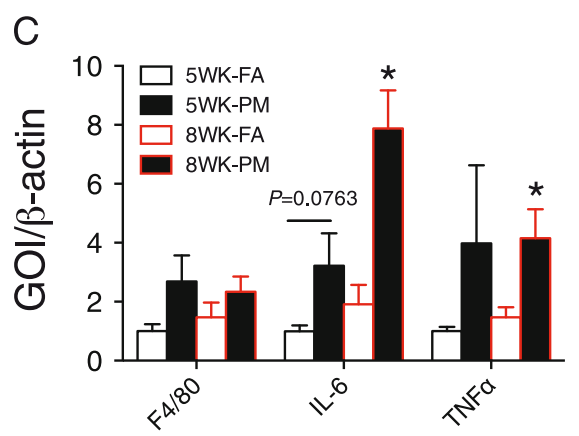

B

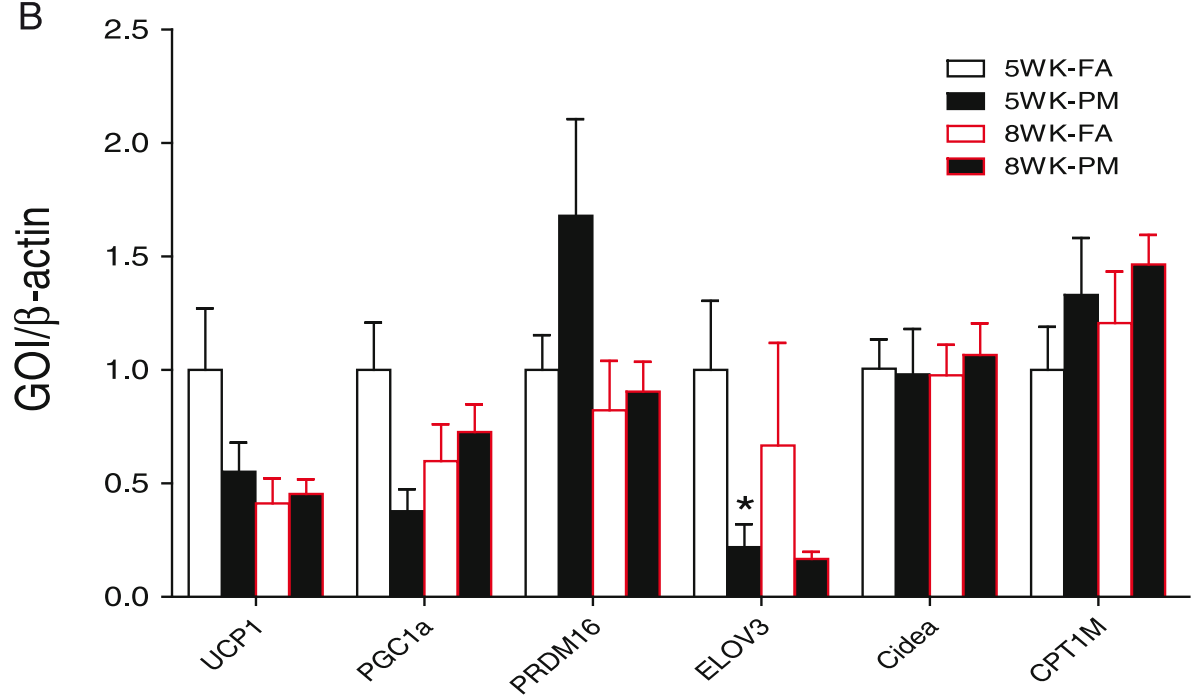

Figure 7 Effect of $\mathbf{P M}_{2.5}$ exposure on BAT-specific gene profiles and UCP1 expression in KKay mice. (A), Altered protein levels of UCP1 in interscapular BAT in response to $\mathrm{PM}_{2.5}$ exposure. (B), Altered mRNA levels of BAT-specific gene profiles in BAT in response to $\mathrm{PM}_{2.5}$ exposure. (C), Expression of inflammation-related genes in BAT in response to $\mathrm{PM}_{2.5}$ exposure. ${ }^{*} P<0.05$ compared to respective $\mathrm{FA}$ group. $\mathrm{n}=6-8$ per group. uncoupling protein 1 (UCP1), peroxisome proliferator-activated receptor- $\gamma$ coactivator 1-a (PGC-1a), PRD1-BF1-RIZ1 homologous domain containing 16 (PRDM 16), elongation of very long chain fatty acid 3 (ELOV3), Cell death-inducing DNA fragmentation factor-like effector A (Cidea), Carnitine palmitoyltransferase 1 muscle isoform (CPT-1 M).

mechanisms by which leptin expression is regulated need further study. The net action of leptin is to inhibit appetite, stimulate thermogenesis, enhance fatty acid oxidation, decrease glucose, and thus reduce body weight and fat through central mechanisms [27]. Recent studies have suggested that central leptin resistance may contribute to attenuation of the well known effects of leptin. Since the circulating leptin levels in our studies were increased in response to $\mathrm{PM}_{2.5}$ exposure, our results raise the possibility of leptin resistance as an additional component and will need further study. Consistent with our findings, Bremer et al. demonstrated the novel observation that adipose tissue in subjects with nascent metabolic syndrome have increased levels of leptin as well as decreased levels of adiponectin and omentin-1, concomitant with increased adipokines such as IL-1, IL-6, IL-8, PAI-1 and MCP1 [28,29]. Thus it can be assumed that adipose tissue dysregulation and aberrant adipokine secretion contribute towards the syndrome's low-grade chronic proinflammatory state and IR accompanied by correction for increased adiposity in the current KKay mice.

A number of studies have highlighted the innate immune mechanisms as the critical role that is responsible for the pathophysiological abnormalities, including IR. In line with this, our results demonstrated that although $\mathrm{PM}_{2.5}$ inhalation did not enhance inflammotary cytokines production in blood, it did result in increased circulating inflammatory monocytes (CD11b+/7/4hi/Gr-1low) accompanied by a corresponding reduction in bone marrow. We have previously demonstrated this same finding in our earlier studies and shown an important role for TLR4 in mobilization of inflammatory subsets of monocytes in response to $\mathrm{PM}_{2.5}$ exposure [13]. This subset is believed to mediate pro-inflammatory effects and a decrease in this population has been associated with favorable end-points including regression of atherosclerotic lesions and macrophage accumulation [30]. It is well known that monocytes 


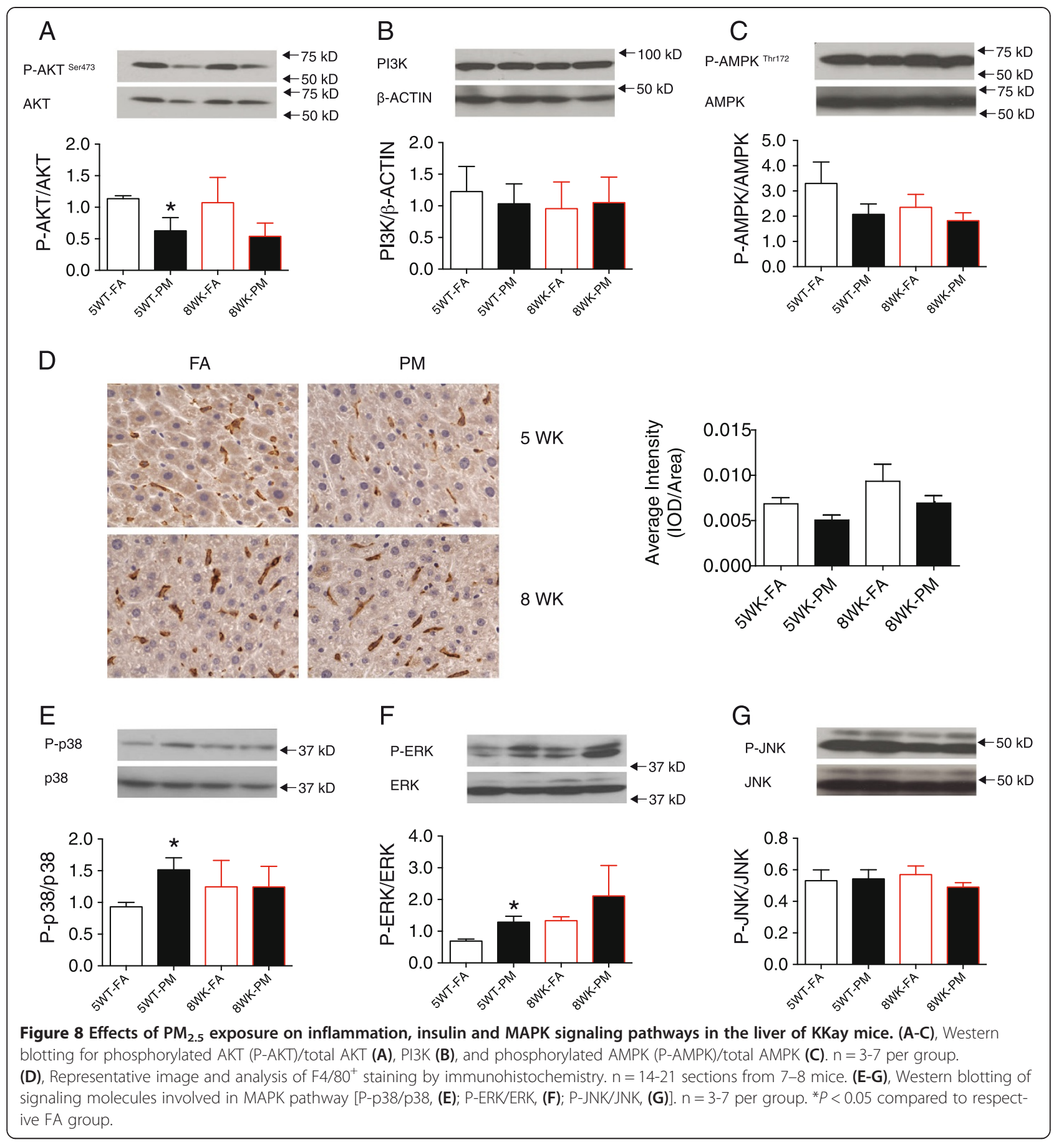

originate from progenitors in the bone marrow and traffic via the bloodstream to peripheral tissues [31]. As a homeostatic response to diverse triggers, circulating monocytes leave the bloodstream and migrate into tissues where, they differentiate into macrophage or dendritic cell populations following conditioning by local growth factors such as pro-inflammatory cytokines and microbial products [31]. $\mathrm{F} 4 / 80^{+} / \mathrm{CD} 11 \mathrm{c}^{+}$is a widely used marker to label "classically activated" macrophages that have been demonstrated to play a pathophysiological role in high-fat diet-induced obesity [26,32-34]. Our findings in this study extend our previous observations where we have shown increased macrophage infiltration into VAT in response to concentrated $\mathrm{PM}_{2.5}$ exposure, in excess of the effects of high-fat diet alone [6]. Furthermore, the macrophages in VAT in mice exposed to $\mathrm{PM}_{2.5}\left(72.7 \mu \mathrm{g} / \mathrm{m}^{3}, 128\right.$ days) demonstrated an "M1" profile with increased cytokines such as TNF $\alpha$ and IL-6, and reduced expression of IL-10 and $\mathrm{N}$-acetyl-galactosamine 
specific lectin 1 [6]. Using a mouse model with yellow fluorescent protein (YFP)-expressing monocytes $\left(\mathrm{c}-f m s^{\mathrm{YFP}}\right)$, we further confirmed enhanced monocyte adhesion in microcirculation of VAT and accumulation in visceral fat [6]. The increased monocyte/macrophage infiltration in VAT in response to $\mathrm{PM}_{2.5}$ exposure further appears to be dependent on CCR2 $\left(116.9 \pm 34.2 \mu \mathrm{g} / \mathrm{m}^{3}, \sim 17\right.$ weeks), as it was abolished by genetic ablation of CCR2 [19]. Thus, the increased population of $\mathrm{F} 4 / 80^{+} / \mathrm{CD} 11 \mathrm{c}^{+}$in eWAT suggest mechanisms similar to those involved in diet mediated aggravation of the VAT infiltration via CCR2-dependent pathways [33]. Except for the increase in excess oxidative and nitrosative stress in BAT after long term $\mathrm{PM}_{2.5}$ exposure [7], we demonstrated in the current study that $\mathrm{PM}_{2.5}$-mediated upregulation of pro-inflammatory genes in BAT and provided additional explanation for the inhibited energy metabolism. Together with the redirection of Th1/Th2 balance towards a Th1 polarized state in response to $\mathrm{PM}_{2.5}$ exposure (Figure $5 \mathrm{~B}$ ), these results suggest the increased inflammation in visceral WAT, BAT and Th1 polarization in spleen indicated recruitment of monocytes into tissues, therefore, contributed to the pathogenesis of inflammatory diseases such as IR or diabetes.

p38 MAPK belongs to a family of evolutionarily conserved serine-threonine MAPKs that link extracellular signals to intracellular machinery regulating a plethora of cellular processes. Together with JNK, they are activated by environmental or genotoxic stress and described as stress-activated protein kinases [35-37]. Different from the observation with $\mathrm{PM}_{2.5}$-exposed $\mathrm{C} 57 \mathrm{BL} / 6$ mice fed on regular chaw by Zheng et al. [38], we found activation of p38 and ERK but not JNK in response to $\mathrm{PM}_{2.5}$ in the KKay mice. These differences likely represent differences in strains and genetic susceptibility, in addition to the complex interactions of diet and environmental signals. In keeping a line with our study, Jiao et al. have suggested that the increased hepatic ERK activity may contribute to increased liver glycogen content and decreased energy expenditure in obesity and may play a central role in hepatic glucose and lipid metabolism $[39,40]$. However, whether increased MAPKs activity is causal or a homeostatic consequence remains to be determined as others have suggested that increases in p38 activity may regulate Xbp1 nuclear translocation and activity and thus may represent a compensatory mechanism to maintain homeostatic response [41]. Therefore, the significance of these findings and precise role of $\mathrm{p} 38$ warrants further studies.

In summary, our results suggest that particulate air pollution exposure resulted in dysregulated metabolism and influenced IR likely through complex pathways involving the liver, visceral and brown adipose tissue in a genetic KKay diabetes model. These findings suggest an important role for $\mathrm{PM}_{2.5}$ in modulating susceptibility to
Type II DM and may have important implications for public health at a global scale.

\section{Additional file}

Additional file 1: Figure S1. $\mathrm{PM}_{2.5}$ concentration to which mice were exposed at the study site. Figure $\mathbf{S 2}$. Effect of $\mathrm{PM}_{2.5}$ exposure on vascular function from KKay mice. A, Dose-response to phenylephrine, acetylcholine and intraluminal pressure in small mesenteric artery at the end of $\mathrm{PM}_{2.5}$ exposure. B, Dose response to acetylcholine and insulin in in aortic rings precontracted with phenylephrine at the end of $\mathrm{PM}_{2.5}$ exposure. ${ }^{*} P<0.05$ compared to FA group. $n=5-8$ per group.

\section{Abbreviations}

BAT: Brown adipose tissue; FA: Filtered air; IR: Insulin resistance; ITT: Insulin tolerance test; IPGT: Intra-peritoneal glucose tolerance testing; PM: Particulate matter; $\mathrm{PM}_{2.5}$ : Particulate matter $<2.5 \mu \mathrm{m}$ in aerodynamic diameter; Type II DM: Type II diabetes; UCP1: Uncoupling protein 1; eWAT: Epididymal white adipose tissue.

\section{Competing interests}

The authors declare that they have no competing interests.

\section{Authors' contributions}

$C L, Y B, X X, A W, T W, Z Y, S M$ and MM performed the experiments and contributed to acquisition of data. $C L, Z Y$, and $S M$ analyzed the data and interpreted the results. AW contributed to $\mathrm{PM}_{2.5}$ exposure of the animals. The manuscript was written by $C L$ and revised critically by $S R, Q S, L S, M P$ and JTD. All authors read, corrected and approved the manuscript.

\section{Acknowledgements}

This work was supported by National Institute of Environmental Health Sciences (NIEHS) grants R01-ES-017290, R01-ES-015146, and R01-ES-019616 (to Dr. Rajagopalan) and R01-ES-018900 to Dr. Sun. It was also made possible by USEPA grant RD83479701 (to Dr. Rajagopalan and Dr. Harkema) and Zhejiang Provincial Natural Science Foundation of China LQ13H070002 (to Dr. Liu).Its contents are solely the responsibility of the grantee and do not necessarily represent the official views of the USEPA. Further, USEPA does not endorse the purchase of any commercial products or services mentioned in the publication.

\section{Author details}

${ }^{1}$ Department of Physiology, Hangzhou Normal University, Hangzhou, China. ${ }^{2}$ Wexner Medical Center, The Ohio State University, Columbus, OH, USA. ${ }^{3}$ Division of Cardiovascular Medicine, The Affiliated Hospital of Chengde Medical College, Chengde, China. ${ }^{4}$ Department of Environmental Health Sciences, University of Michigan, Ann Arbor, MI, USA. ${ }^{5}$ Center for Integrative Toxicology, Michigan State University, Lansing, MI, USA. ${ }^{6}$ Division of Cardiovascular Medicine, University of Maryland, Baltimore, MD, USA.

Received: 1 October 2013 Accepted: 16 May 2014 Published: 30 May 2014

\section{References}

1. Lim SS, Vos T, Flaxman AD, Danaei G, Shibuya K, Adair-Rohani H, Amann M, Anderson HR, Andrews KG, Aryee M, Atkinson C, Bacchus LJ, Bahalim AN, Balakrishnan K, Balmes J, Barker-Collo S, Baxter A, Bell ML, Blore JD, Blyth F, Bonner C, Borges G, Bourne R, Boussinesq M, Brauer M, Brooks P, Bruce NG, Brunekreef B, Bryan-Hancock C, Bucello C, et al: A comparative risk assessment of burden of disease and injury attributable to 67 risk factors and risk factor clusters in 21 regions, 1990-2010: a systematic analysis for the Global Burden of Disease Study 2010. Lancet 2012, 380:2224-2260.

2. Brook RD, Rajagopalan S, Pope CA 3rd, Brook JR, Bhatnagar A, Diez-Roux AV, Holguin F, Hong Y, Luepker RV, Mittleman MA, Peters A, Siscovick D, Smith SC Jr, Whitsel L, Kaufman JD, American Heart Association Council on Epidemiology and Prevention, Council on the Kidney in Cardiovascular Disease, and Council on Nutrition, Physical Activity and Metabolism: Particulate matter air pollution and cardiovascular disease: An update to the scientific statement from the American Heart Association. Circulation 2010, 121:2331-2378. 
3. Hotamisligil GS: Endoplasmic reticulum stress and the inflammatory basis of metabolic disease. Cell 2010, 140:900-917.

4. Hotamisligil GS: Inflammation and metabolic disorders. Nature 2006, 444:860-867.

5. Gregor MF, Hotamisligil GS: Inflammatory mechanisms in obesity. Annu Rev Immunol 2011, 29:415-445.

6. Sun $Q$, Yue $P$, Deiuliis JA, Lumeng CN, Kampfrath T, Mikolaj MB, Cai Y, Ostrowski MC, Lu B, Parthasarathy S, Brook RD, Moffatt-Bruce SD, Chen LC, Rajagopalan S: Ambient air pollution exaggerates adipose inflammation and insulin resistance in a mouse model of diet-induced obesity. Circulation 2009, 119:538-546.

7. Xu X, Liu C, Xu Z, Tzan K, Zhong M, Wang A, Lippmann M, Chen LC, Rajagopalan S, Sun Q: Long-term exposure to ambient fine particulate pollution induces insulin resistance and mitochondrial alteration in adipose tissue. Toxicol Sci 2011, 124:88-98.

8. Xu X, Yavar Z, Verdin M, Ying Z, Mihai G, Kampfrath T, Wang A, Zhong M, Lippmann M, Chen LC, Rajagopalan S, Sun Q: Effect of early particulate air pollution exposure on obesity in mice: role of p47phox. Arterioscler Thromb Vasc Biol 2010, 30:2518-2527.

9. Liu CQ, Leung FP, Wong SL, Wong WT, Lau CW, Lu L, Yao X, Yao T, Huang $Y$ : Thromboxane prostanoid receptor activation impairs endothelial nitric oxide-dependent vasorelaxations: the role of Rho kinase. Biochem Pharmacol 2009, 78:374-381.

10. Chan YC, Leung FP, Wong WT, Tian XY, Yung LM, Lau CW, Tsang SY, Yao X, Chen $Z Y$, Huang $Y$ : Therapeutically relevant concentrations of raloxifene dilate pressurized rat resistance arteries via calcium-dependent endothelial nitric oxide synthase activation. Arterioscler Thromb Vasc Biol 2010, 30:992-999.

11. Furukawa S, Fujita T, Shimabukuro M, Iwaki M, Yamada Y, Nakajima Y, Nakayama O, Makishima M, Matsuda M, Shimomura I: Increased oxidative stress in obesity and its impact on metabolic syndrome. J Clin Invest 2004, 114:1752-1761.

12. Sultan A, Strodthoff D, Robertson AK, Paulsson-Berne G, Fauconnier J, Parini $P$, Ryden M, Thierry-Mieg N, Johansson ME, Chibalin AV, Zierath JR, Arner $P$, Hansson GK: T cell-mediated inflammation in adipose tissue does not cause insulin resistance in hyperlipidemic mice. Circ Res 2009, 104:961-968.

13. Kampfrath T, Maiseyeu A, Ying Z, Shah Z, Deiuliis JA, Xu X, Kherada N, Brook RD, Reddy KM, Padture NP, Parthasarathy S, Chen LC, Moffatt-Bruce S, Sun Q, Morawietz H, Rajagopalan S: Chronic fine particulate matter exposure induces systemic vascular dysfunction via NADPH oxidase and TLR4 pathways. Circ Res 2011, 108:716-726.

14. Dandona P, Aljada A, Bandyopadhyay A: Inflammation: the link between insulin resistance, obesity and diabetes. Trends Immunol 2004, 25:4-7.

15. Shoelson SE, Lee J, Goldfine AB: Inflammation and insulin resistance. $J$ Clin Invest 2006, 116:1793-1801.

16. Xu H, Barnes GT, Yang Q, Tan G, Yang D, Chou CJ, Sole J, Nichols A, Ross JS, Tartaglia LA, Chen H: Chronic inflammation in fat plays a crucial role in the development of obesity-related insulin resistance. J Clin Invest 2003, 112:1821-1830.

17. Ricquier D: Mitochondrial uncoupling proteins. Curr Opin Drug Discov Devel 1999, 2:497-504.

18. Richard D, Picard F: Brown fat biology and thermogenesis. Front Biosci 2011, 16:1233-1260.

19. Liu C, Xu X, Bai Y, Wang TY, Rao X, Wang A, Sun L, Ying Z, Gushchina L, Maiseyeu A, Morishita M, Sun Q, Harkema JR, Rajagopalan S: Air PollutionMediated Susceptibility to Inflammation and Insulin Resistance: Influence of CCR2 Pathways in Mice. Environ Health Perspect 2014, 122:17-26.

20. Cypess AM, Kahn CR: Brown fat as a therapy for obesity and diabetes. Curr Opin Endocrinol Diabetes Obes 2010, 17:143-149.

21. Cypess AM, Kahn CR: The role and importance of brown adipose tissue in energy homeostasis. Curr Opin Pediatr 2010, 22:478-484.

22. Wu J, Cohen P, Spiegelman BM: Adaptive thermogenesis in adipocytes: is beige the new brown? Genes Dev 2013, 27:234-250.

23. Ricquier D: Respiration uncoupling and metabolism in the control of energy expenditure. Proc Nutr Soc 2005, 64:47-52

24. Xu X, Liu C, Xu Z, Tzan K, Wang A, Rajagopalan S, Sun Q: Altered adipocyte progenitor population and adipose-related gene profile in adipose tissue by long-term high-fat diet in mice. Life Sci 2012, 90:1001-1009.

25. Fromme T, Klingenspor M: Uncoupling protein 1 expression and high-fat diets. Am J Physiol Regul Integr Comp Physiol 2011, 300:R1-R8.
26. Weisberg SP, McCann D, Desai M, Rosenbaum M, Leibel RL, Ferrante AW Jr: Obesity is associated with macrophage accumulation in adipose tissue. J Clin Invest 2003, 112:1796-1808.

27. Yadav A, Kataria MA, Saini V: Role of leptin and adiponectin in insulin resistance. Clin Chim Acta 2013, 417:80-84.

28. Bremer AA, Devaraj S, Afify A, Jialal I: Adipose tissue dysregulation in patients with metabolic syndrome. J Clin Endocrinol Metab 2011, 96:E1782-E1788

29. Bremer AA, Jialal I: Adipose tissue dysfunction in nascent metabolic syndrome. J Obes 2013, 2013:393192.

30. Combadiere C, Potteaux S, Rodero M, Simon T, Pezard A, Esposito B, Merval $R$, Proudfoot A, Tedgui A, Mallat Z: Combined inhibition of CCL2, CX3CR1, and CCR5 abrogates Ly6C (hi) and Ly6C (lo) monocytosis and almost abolishes atherosclerosis in hypercholesterolemic mice. Circulation 2008 , 117:1649-1657.

31. Shi C, Pamer EG: Monocyte recruitment during infection and inflammation. Nat Rev Immunol 2011, 11:762-774.

32. Lumeng CN, Bodzin JL, Saltiel AR: Obesity induces a phenotypic switch in adipose tissue macrophage polarization. J Clin Invest 2007, 117:175-184.

33. Tsou CL, Peters W, Si Y, Slaymaker S, Aslanian AM, Weisberg SP, Mack M, Charo IF: Critical roles for CCR2 and MCP-3 in monocyte mobilization from bone marrow and recruitment to inflammatory sites. J Clin Invest 2007, 117:902-909.

34. Lumeng CN, Deyoung SM, Saltiel AR: Macrophages block insulin action in adipocytes by altering expression of signaling and glucose transport proteins. Am J Physiol Endocrinol Metab 2007, 292:E166-E174.

35. Chang L, Karin M: Mammalian MAP kinase signalling cascades. Nature 2001, 410:37-40.

36. Coulthard LR, White DE, Jones DL, McDermott MF, Burchill SA: p38(MAPK): stress responses from molecular mechanisms to therapeutics. Trends $\mathrm{Mol}$ Med 2009, 15:369-379.

37. Morrison DK, Davis RJ: Regulation of MAP kinase signaling modules by scaffold proteins in mammals. Annu Rev Cell Dev Biol 2003, 19:91-118.

38. Zheng Z, Xu X, Zhang X, Wang A, Zhang C, Huttemann M, Grossman LI, Chen LC, Rajagopalan S, Sun Q, Zhang K: Exposure to Ambient Particulate Matter Induces a NASH-like Phenotype and Impairs Hepatic Glucose Metabolism in an Animal Model. J Hepatol 2012, 58:148-154.

39. Jiao P, Feng B, Li Y, He Q, Xu H: Hepatic ERK activity plays a role in energy metabolism. Mol Cell Endocrinol 2013, 375:157-166.

40. Liu Z, Cao W: p38 mitogen-activated protein kinase: a critical node linking insulin resistance and cardiovascular diseases in type 2 diabetes mellitus. Endocr Metab Immune Disord Drug Targets 2009, 9:38-46.

41. Lee J, Sun C, Zhou Y, Gokalp D, Herrema H, Park SW, Davis RJ, Ozcan U: p38 MAPK-mediated regulation of Xbp1s is crucial for glucose homeostasis. Nat Med 2011, 17:1251-1260.

doi:10.1186/1743-8977-11-27

Cite this article as: Liu et al:: Exaggerated effects of particulate matter air pollution in genetic type II diabetes mellitus. Particle and Fibre Toxicology 2014 11:27.

\section{Submit your next manuscript to BioMed Central and take full advantage of:}

- Convenient online submission

- Thorough peer review

- No space constraints or color figure charges

- Immediate publication on acceptance

- Inclusion in PubMed, CAS, Scopus and Google Scholar

- Research which is freely available for redistribution 